\title{
Development of Self-Explanation Prompt in $i$-Fractions
}

\author{
Ummu Husna Azizan, Nor Zuhaidah Mohamed Zain Shamsul Arrieya Ariffin
}

\begin{abstract}
The purpose of this study is to design a selfexplanation prompts or help element in iFractions educational game software. The self-explanation prompts was developed using the cartoon concept. In the previous research students who used the self-explanation prompts showed significantly better achievements. Students who used iFractions with selfexplanation prompts found that it has helped them make the fractions abstract concept concrete and facilitate the proper construction of fractions schema. Therefore, the design of any educational software must be constructive in parallel with the combination of scaffolding element which is the self-explanation prompts.
\end{abstract}

Keywords: Self- explanation prompts; cartoon concept; fractions

\section{INTRODUCTION}

Fractions is a very difficult topic for school children (Gabriel et.al., 2013; Forgues, Tian and Siegler 2015; Tian and Siegler 2016;Emily Sharp and Dennis, 2017). This occurs since students cannot construct a proper fractions schema due to the confusion that arises when learning the topic of Round Numbers. Hence, previous researchers have developed various teaching aids to solve problems that arose in learning fractions. One of the teaching aids developed by previous researchers was an educational software in the form of games and non-games. However, the software developed had many weaknesses in terms of assistance to low ability students. MdSalleh and Napiah (2010) have developed afractions educational software to improve students' performance in fractions. However, this software was not flexible for students with different levels of ability because the help element was not available.

Wan Fatimah and NurulHidayah (2010) have also developed the fractions educational game software that contained tutorials on fractions. The help element was also not provided in this software. The Ministry of Education Malaysia(MOE) has also distributed the educational software, that is the MyCD course software for Year 1 to Year 4 students; containing text, animation, audio, video, interactive activities and interactive tests to support and enhance text book contents (Muhammad, 2009).

Revised Manuscript Received on June 22, 2019.

Ummu Husna Azizan, Faculty of Arts, Computing and Creative Industry, Sultan Idris Education University, PObox35900 Tanjong Malim, Perak, Malaysia

Nor Zuhaidah Mohamed Zain Shamsul Arrieya Ariffin, Faculty of Arts, Computing and Creative Industry, Sultan Idris Education University, PObox35900 TanjongMalim, Perak, Malaysia
However, MyCD did not provide scaffolding elements or help to students to assist low ability students to construct fractions schema. According to Adams and Clark (2014), the current education world still has no clear principles for designing an effective educational game for students. Helping students learn new information is very important especially for low ability students. There are various methods to achieve this goal but not all methods are proven effective. One of the methods is the explanation approach, that is the self-explanation prompts (Durkin, 2011). According to Killingsworth and Clark (2015), selfexplanation prompts is a very effective approach to enhance learning in educational game software. This statement is supported by O'Neil et. al. (2014), where the selfexplanation prompts is a very effective teaching method to help in strengthening the learning schema.

\section{SELF-EXPLANATIONPROMPTS}

The self-explanation prompts is defined as generating self-explanations in order to understand the information learned (Johnson, Loehr and Durkin, 2017; Chi, 2000). According to Chi, Olfman and Berger (2017), selfexplanation is an effective metacognitive strategy that can help students develop deeper understanding since the selfexplanation prompts emphasises on production of conclusions to bridge the information gap in learning materials (Sernlai, Spottl and Straka, 2011) and can be used to support multimedia learning (Lijia Lin et. al,2014).

Studies show that students who are often motivated to carry out self-explanation related to learning materials perform better than students who are not motivated to do self-explanation (Chi, Olfman and Berger, 2017; RittleJohnson and Loehr, 2016; Mayer, Dow and Mayer, 2003; Wong, Lawson, and Keeves, 2002). Most students do not do self-explanation spontaneously but begin to self-explain when guided (Bielaczyc, Pirolli, and Brown, 1995) or when motivated to do so (Chi, DeLeeuw, Chiu, and LaVancher, 1994).

According to Rittle- Johnson (2006), students who are not motivated to do self- explanation will return to using their wrong procedure or understanding. Self-explanation prompts can be carried out through 'thinking-aloud' (talking) or covertly (thinking). According to Roy and Chi (2005), Chi et al. (1989) and Nokes, Hausmann and Van Lehn (2011), self- explanation prompts can play a role in two forms, that is generating conclusions to fill up the missing information (gap-filling) and the mental-model revision. 
Gap-filling is designed to fill in the information gap in such learning while mental-model revision is the driving force that focuses on students to review their existing knowledge. Studies done by Lijia Lin et. al (2014) found that self-explanation prompt can improve students' performance while reducing the students' cognitive burden. This statement is supported by O'Neil et. al. (2014) where he found that self-explanation prompt could help students in the process of playing educational software games.

\section{CartoonConcept}

One of the techniques to create self-explanation prompts is by using cartoon concept which it is used as a stimulus to questions, triggers discussion and generate scientific thinking by assessing existing students' knowledge of certain concept including competing views or explanations of certain phenomena (Long danMarson, 2003; Song, Heo, KrumenakerdanTippins, 2008). Cartoon concept has features such as visual representation of scientific ideas, minimal texts in the form of dialogue, alternative views in every situation, scientific ideas are applied in everyday situations and accepted scientific views and alternative views will be added together (Keogh dan Naylor, 1999).

Cartoon concept is very effective in student learning where it involved students in scientific dialogue to explore scientific concepts (Song, Heo, KrumenakerdanTippins, 2008; Sexton, Gervasonidan Brandenburg, 2009). Student are required to consider the views expressed and determine the views they support and why they support such views (Keogh dan Naylor, 2000).

Cartoon concept involves students in discussion by presenting some alternative views by cartoon characters in which this will cause a debate among students. The alternative views provided include acceptable scientific ideas and the common misconceptions that students have in daily learning. The debate arises when students oppose ideas and disagree with the views given by the cartoon characters (Chin danTeou, 2009). Through cartoon debates and alternatives

views, existingstudentsknowledgewillbecombinedwithnewkn owledgetoreconstructtheirincorrect learning scheme and facilitate the formation of mental models. When a student has a strong mental model, this can help to improve student achievement. An example of cartoon concept design is shown in Figure 1.

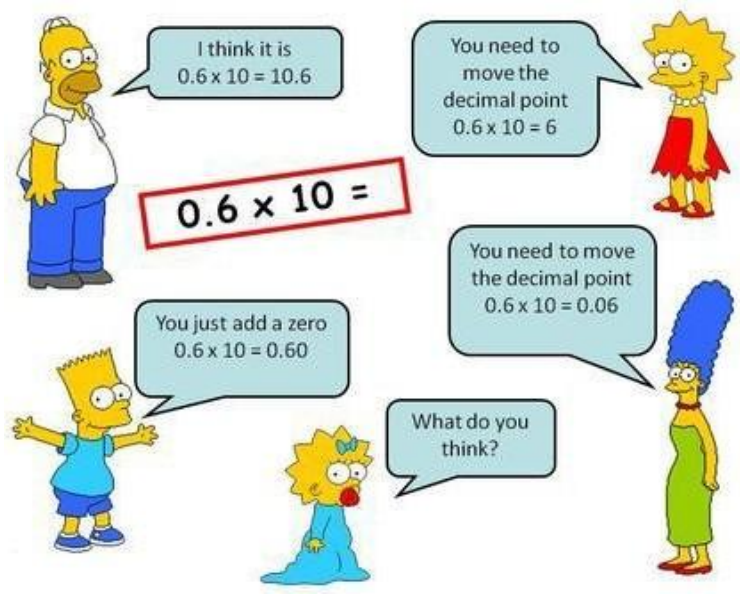

Fig. 1 Example of cartoon concept

\section{Development of Self-Explanation Prompts in $i$ Fractions}

Self-explanation prompts in $i$ Fractions are designed using cartoon concept. The cartoon concept applied the use of a bunch of cartoon characters that dialogue through the use of minimal texts (Sexton, Gervasoni\& Brandenburg, 2009). The self-explanation prompts that were developed in $i$ Fractions consists of meta-cognitive self explanation prompt and justification prompts which are based on three types that is teacher, friends and facebook as in Figure 2.

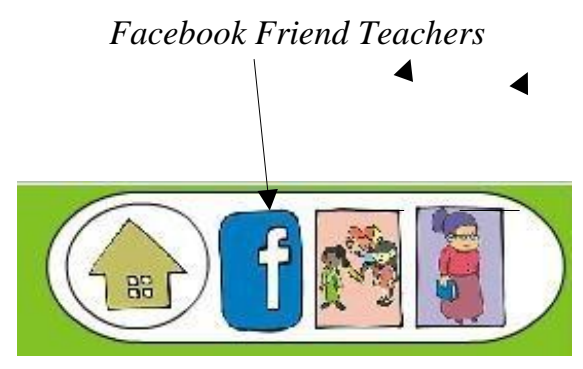

Fig. 2Self-explanation prompts button in $i$ Fractions

Examples of cartoon concepts used in $i$ Fractions development are shown in Figure 3, Figure 4 and Figure 5. Cartoon concept that applied in the development of metacognitive and justification self-explanation prompts involve cartoon characters that are currently discussing about fraction comparison problem that consist of correct and incorrect views and solutions. 


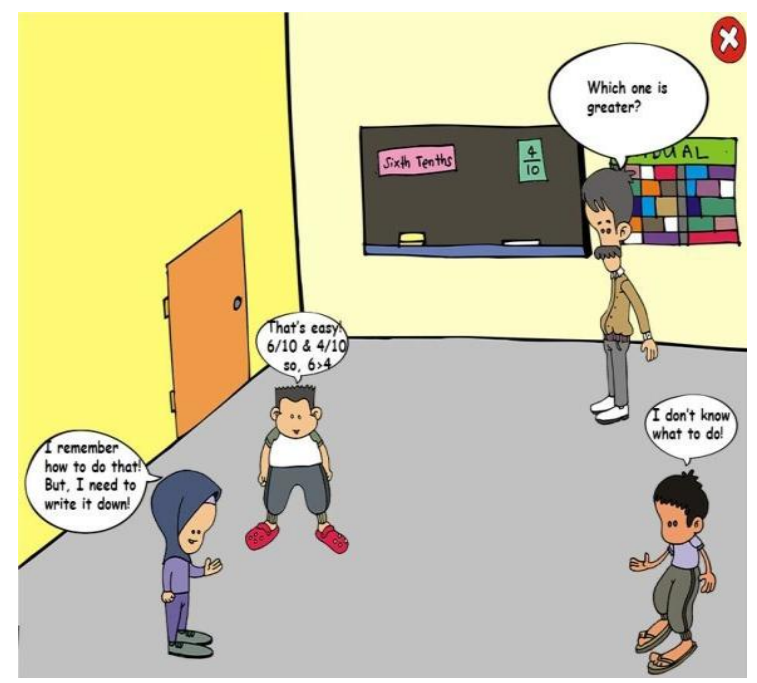

Fig. 3Self-explanation prompt (teacher) iniFractions

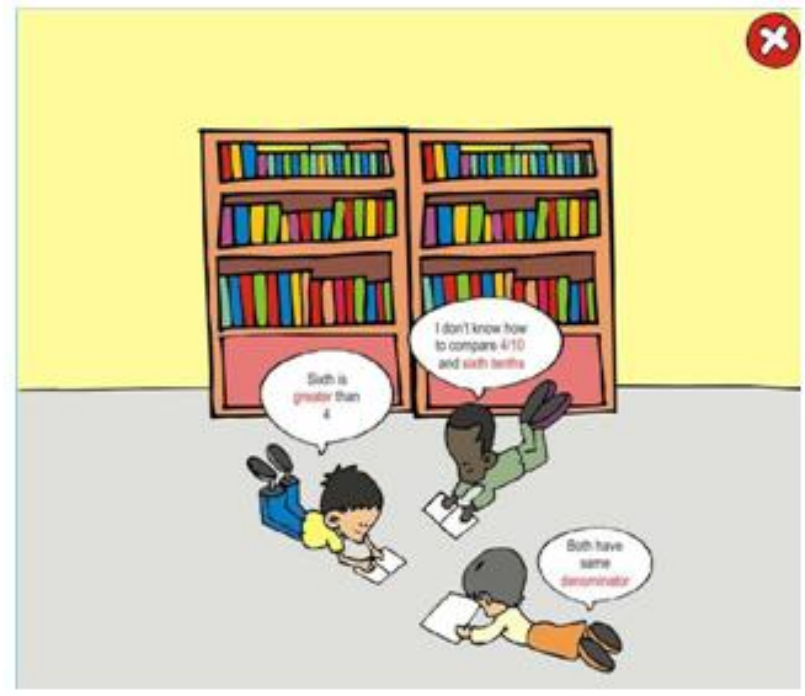

Fig. 4 Self-explanation prompt (friends) iniFractions

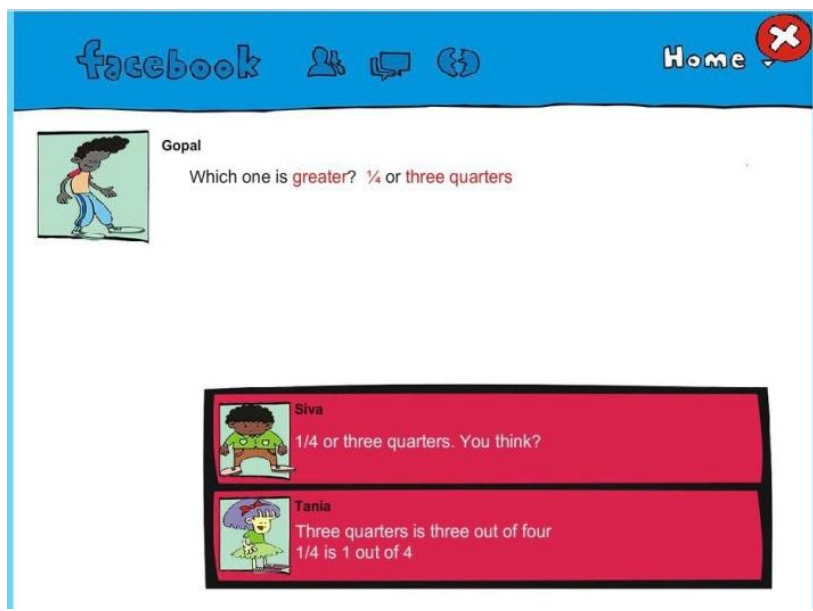

Fig. 5Self-explanation prompt (facebook) in $i$ Fractions

The cartoon shown in Figure 3, Figure 4 and Figure 5 illustrates three to four characters and a dialog that describe each character strategy to solve problem regarding comparison of fractions. Critical elements that are required in comparison of fractions are bolded and writing using red colors as shown in Figure 4 to attract students attention.
These cartoon characters arouse debates and arguments among students if they have conflicting ideas and disagree with their views (Chin danTeou, 2009). Students existing views and concepts will be adapted to the new knowledge received from the debate. Restructuring of the concepts will occur if the student existing concept is wrong or unacceptable until the students can form the correct fraction scheme.

\section{CONCLUSION}

Self-explanation prompts is effective especially for low ability students in improving their fractions achievements. The $i$ Fractions educational game software can trigger selfexplanation among students as a software environment that encourages and assist students to begin their own selfexplanation process among themselves. This is because according to Bielaczyc, Pirolli, and Brown, (1995), most students do not begin the self-explanation process spontaneously unless they are assisted to begin the process of self-explanation or are encouraged to do so (Chi, DeLeeuw, Chiu, \&laVancher, 1994). Due to the weak existing knowledge of students, self- explanation prompts helps activate existing knowledge of students by creating a phenomenon that can trigger conceptual conflicts through different perceptions (Clark, 2008). Different perceptions can create dissatisfaction with the old concept existing in the cognitive structure. In accommodating this, students will alter the concept of inaccuracy with the new phenomenon encountered. The self-explanation prompts developed in this game software helps studentsinconstructing the correct fractions schema by creating perceptions different from the students' perceptions.

\section{ACKNOWLEDGEMENT}

This paper is based on the research project entitled 'RekabentukPendorongPeneranganKendiridalamPerisianPer mainanPendidikaniFraction'. The authors would like to extend their gratitude to the Research Management and Innovation Centre (RMIC), Sultan Idris Education University (UPSI) for the University Research Grants (code: 2016-0056-109-01) that helped fund the research.

\section{REFERENCES}

1. Adams, D. M. \& Clark, D. B. (2014). Integrating self-explanation functionality into a complex game environment: Keeping gaming in motion. Computers \& Education, 73, 149-159.

2. Bielaczyc K., Pirolli P. and Brown A.L. (1995). Training in SelfExplanation and Selfregulation Strategies: Investigating the Effects of Knowledge Acquisition Activities on Problem Solving. Cognition and Instruction. 13(2): 221-252.

3. Chi, M.T.H. (2000). Self-explaining: The Dual Processes of Generating Inference and Repairing Mental Models. Advances in Instructional Psychology: Educational Design and Cognitive Science. 5: 161-238

4. Chi M.T.H., de Leeuw N., Chiu M.H. and LaVancher C. (1994). Eliciting self-Explanations Improves Understanding. Cognitive Science. 18: 439-477. 


\section{Development of Self-Explanation Prompt in $i$-Fractions}

5. Chi, T.Y., Olfman, L. \& Berger, D.E. (2017). Computer Skill Acquisition : The Effects of Computer -aided Self Explanation on Knowledge Retention and Transfer. Proceedings of the 50th Hawail International Conference on System Sciences. http://hdl.handle.net/10125/41160

6. Chi M.T.H., Bassok M., Lewis M.W., Reimann P. and Glaser R. (1989). Self-explanations: How Students Study and Use Examples in Learning to Solve Problems. Cognitive Science. 13: 145- 182.

7. Chin C. and Teou L. (2009). Using Concept Cartoons in Formative Assessment: Scaffolding Students' Argumentation. International Journal of Science Education. 31(10): 1307-1332.

8. Clark R.C. (2008). Building Expertise: Cognitive Methods for Training and Performance Improvement (3rd ed). San Francisco: Pfeiffer.

9. Durkin K. (2011). The Self-Explanation Effect When Learning Mathematics: A Meta-Analysis. Paper presented at the Society for Research on Educational Effectiveness Conferences, Washington.

10. Emily Sharp, MS. \& Dennis, M.S. (2017). Model Drawing Strategy for Fraction Word Problem Solving of Fourth-Grade Students With Learning Disabilities. SAGE journals, 38 (3), 181-192.

11. Forgues, H.L., Tian, J. and Siegler, R.S. (2015). Why is learning fraction and decimal arithmetic so difficult?.ELSEVIER, 38, 201-221.

12. Gabriel F, Coché F, Szucs D, Carette V, Rey B, Content A. A componential view of children's difficulties in learning fractions. Frontiers in Psychology. 2013;4 doi: 10.3389/fpsyg.2013.00715[PMC free article][PubMed]

13. Johnson, B.R., Loehr, A.M. \& Durkin, K. (2017). Promoting self explanation to improve mathematics learning: A meta-analysis and instructional design principles. ZDM Mathematics Education, 49, 599611.

14. Keogh B. and Naylor S. (1999). Concept Cartoons, Teaching and Learning in Science: An evaluation. International Journal of Science Education. 21(4): 431-446.

15. Keogh B. and Naylor S. (2000). Teaching and Learning in Science Using Concept Cartoons : Why Dennis Wants to Stay in at Playtime. Australian Primary \& Junior Science Journal. 16(3): 10-14.

16. Killingsworth, S.S. \& Clark, D.B. (2015). Self-Explanation and Explanatory Feedback in Games: Individual Differences, Gameplay, and Learning. International Journal of Education in Mathematics, Science and Technology, 3(3), 162-186.

17. Lijia Lin, Atkinson R. K., Savenye W. C. \& Nelson B. C. (2014) Effects of visual cues and self- explanation prompts: empirical evidence in a multimedia environment, Interactive LearningEnvironments.http://dx.doi.org/10.1080/10494820.2014.9245 31

18. Long S. and Marson K. (2003). Concept Cartoons. Hands on Science. 19(3).

19. Mayer R. E., Dow G.T. and Mayer S. (2003). Multimedia Learning in an Interactive Self- Explaining Environment: What Works in the Design of Agent-Based Microworlds? Journal of Educational Psychology. 95(4): 806-812.

20. MdSalleh S. \&Napiah S.R. (2010). Pembangunan PerisianPembelajaranBerbantukanKomputer (PBK) UntukTopikPecahanTingkatanSatuMenggunakanPendekatanMasteri. Skudai: UniversitiTeknologiMalaysia.

21. Muhammad N. (2009). KajianPenilaiandanPenggunaan CD ROM PendidikanSainsdanMatematikBagiSekolahMenengahKebangsaan. Master Thesis. Johor. UniversitiTeknologi Malaysia.

22. Nokes T.J., Hausmann R.G.M. and VanLehn K. (2011). Testing the Instructional Fit Hypothesis: The Case of Self-Explanation Prompts. Instruction Science. 39: 645-666.

23. O'Neil et. al. (2014). Adding self-explanation prompts to an educational computer game. Computers in Human Behavior 30 (2014) 23-28

24. Rittle-Johnson B. (2006). Promoting Transfer: Effects of SelfExplanation and Direct Instruction. Child Development. 77(1):1-15.

25. Rittle-Johnson, B \&Loehr, A.M. (2016). Eliciting explanations: Constraints on when self- explanation aids learning. Psychonomic Bulletin \& Review, 24 (5), 1501-1510.

26. Roy M., and Chi M. T. H. (2005). The Self-Explanation Principle in Multimedia Learning. In R.E. Mayer (Ed.). Cambridge Handbook of Multimedia Learning (pp. 413-432). New York: Cambridge University Press.

27. Sern Lai C., Spottl G. \&Straka G.A. (2011). Learning With Workedout Problems in Manufacturing Technology: The Effects of
Instructional Explanations and Self-Explanation Prompts on Acquired Knowledge Acquisition, Near and Far Transfer Performance. Bremen, Institute Technique and Building.

28. Sexton M., Gervasoni A. and Brandenburg R. (2009). Using a Concept Cartoon to Gain Insight Into Children's Calculation Strategies. Australian Primary Mathematics Classroom. 14(4): 24- 28.

29. Song Y., Heo M., Krumenaker L. and Tippins D. (2008). Cartoons-An Alternative Learning Assessment. Science Scope. 31(5): 16-21.

30. Tian, J. \&Siegler, R.S., (2016). Fractions Learning in Children With Mathematics Difficulties.Journal of Learning Disabilities, 1-7.

31. Wan Fatimah W.A. \&NurulHidayah A.L. (2010). Development of a Mathematics Courseware: Fractions. Perak: UniversitiTeknologi PETRONAS.

32. Wong R.M.F., Lawson M.J. and Keeves J. (2002). The Effects of SelfExplanation Training on Students' Problem Solving in High-School Mathematics. Learning and Instruction. 12(2): 233- 262 